\title{
CLINICAL, LABORATORY AND MANAGEMENT PROFILE OF LIVER ABSCESS PATIENTS AT A TERTIARY CARE HOSPITAL IN VINDHYA REGION
}

\section{General Surgery}

Dr Vineeth Kumar Junior Resident, Department of Surgery, Shyam shah Medical College, Rewa. RK* *Corresponding Author

\section{Dr Ambuj Kumar} Soni

Senior Resident, Department of Surgery, Shyam shah Medical College, Rewa.

\section{Dr Ashish Pratap} Singh Dr Priyank Sharma
Assistant Professor, Department of Surgery, Shyam shah Medical College,Rewa

Professor, Department of Surgery, Shyam shah Medical College, Rewa

\begin{abstract}
Liver abscess continues to be an important and a common cause of morbidity in tropical countries especially India.

OBJECTIVE:The purpose of this study is to assess the clinical, laboratory and management profile of liver abscess patients as well as to compare various management modalities.

MATERIALS \& METHODS :In this study for a duration of one year from June 2019 to July 2020150 confirmed liver abscess patients were selected at a tertiary care hospital (Sanjay Gandhi Memorial Hospital, Rewa) in Vindhya Region of India. Careful recording of clinical profile was done along with blood haemogram, liver and renal function tests, prothrombin time was send at the time of admission.Chest Xray was done. Medical management was the primary modality of the treatment whereas majority of the patients required some form of surgical intervention later on Ultrasonography was done for primary diagnosis and was repeated every $3^{\text {rd }}$ day to assess treatment response.

RESULTS :The mean age was 42.54 . Majority of them were males $(92 \%)$ with history of alcoholism (88.4\%). Most common symptom and sign were right upper quadrant pain (74\%) and tenderness in right hypochondrium (93.8\%) respectively. Majority of the patients had raised total leucocyte count $(92.67 \%)$, alkaline phosphatase $(81.33 \%)$, Prothrombin time $(86 \%)$. Right lobe abscess was most common( $82.67 \%)$ and was solitary(58.67\%). 20(13.33\%) patients recovered by conservative management. Out of the rest 130 patients $63.08 \%$ required percutaneous aspiration, $33.85 \%$ underwent pigtail insertion and $3.08 \%$ had laparotomy.
\end{abstract}

\section{KEYWORDS}

liver abscess, ultrasonography, percutaneous aspiration, pigtail drainage.

\section{INTRODUCTION}

Liver abscess (LA) is defined as collection of purulent material in liver parenchyma which can be due to bacterial, parasitic, fungal or mixed infection. Out of total incidence of LA approximately two-thirds of cases in developing countries are of amoebic etiology and threefourths of cases in developed countries are pyogenic ${ }^{[1]}$ It may be due to bacterial or parasitic invasion of liver. Majority of abscesses are multiple which are due to biliary system and arterial circulation and subdiaphragmatic and are noted in the right lobe of liver. Solitary or single abscess is due to portal circulation, cryptogenic and trauma. Early studies by Oschner et al. recommended open surgical drainage as the treatment of choice. Surgical management was the mainstay for treating LA earlier ${ }^{[1]}$. However recent evidences from percutaneous drainage procedure have shown a favorable outcome with less average length of stay in hospital compared to conservative mode of treatment

\section{AIMS AND OBJECTIVES}

1. To analyse the various modes of clinical presentation of liver abscess.

2. To analyse various laboratory and radiological parameters in case of liver abscess.

3. Comparison between various management methods

\section{MATERIALS AND METHODS}

This was a prospective study in the Department General Surgery, Sanjay Gandhi Memorial Hospital, Rewa , Madhya Pradesh (India) during the period of June 2019- July 2020.150 consecutive patients diagnosed as having liver abscess on ultrasound were included in the study after taking informed written consent.

Patients with following conditions were excluded

- Patients having other liver disease such as malignancies, CLD.

- Pediatric age group.

- Post-traumatic liver abscess.

A careful history was taken from all the patients. Using modified Kuppuswamy's Socioeconomic Status scale, patients were divided into three socioeconomic classes: upper, middle, and lower ${ }^{[2]}$.Detailed history of patient will be entered in proforma. Examination of the patient was done and the findings were recorded. Complete haemogram, Liver and Renal Function Test, Prothrombin time, sent immediately on presentation. Chest Xray and USG abdomen was done on all patients. All patients were started empirically on IV cephalosporins and IV Metronidazole (2.4gm/day) in divided doses. Prophylactic Vitamin K injection were given to all patients for three days. In patients with large liver abscess $(>5 \mathrm{~cm})$ and those not resolved by conservative management required surgical intervention. After taking informed consent, these patients were subjected to ultrasound guided aspiration of liver abscess either by percutaneous needle or pigtail catheter. For ruptured liver abscess laparotomy was done.

Statistical analysis : Statistical analysis was done and $\mathrm{P}$ value $<0.05$ was considered as significant.

\section{RESULTS}

Most of the patients who presented with Liver Abscess were in the middle age with highest incidence in 31 to 40 years age group with 42.54 years as mean age. Most of the patients were male $(92 \%, \mathrm{n}=138)$ and females $(8 \%, \mathrm{n}=12)$ with male to female ratio of $11.5: 1$. All the patients in this study group presented with abdominal pain $(100 \%)$ having right upper quadrant pain(74\%), whole abdomen in $16 \%$ followed by epigastric and left upper quadrant $(1.33 \%)$. Rest of the complaints were fever $(89.6 \%)$, loss of appetite(48\%)nausea and/or vomiting in $42.5 \%$.Cough was seen in $34.2 \%$ of the study group. Only $22 \%$ of the patients gave a history of diarrhea. Most of the patients were found to be alcoholics (88.4\%)Most of the patients didn't have any other comorbid conditions. Most common comorbidity found in our study was diabetes mellitus in 8 patients followed by hypertension in 4 patients. Almost all of the patients were in poor socioeconomic class $(95.33 \%)$ Most common clinical sign found in our study was tenderness in right hypochondrium $(93.8 \%, \mathrm{n}=141)$ followed by localized guarding in $42.6 \%$. Hepatomegaly was found only in $28 \%(\mathrm{n}=42)$ in which the borders were round and surface was smooth on palpation in all the cases. Shifting dullness in 4 cases(2.67\%)which were the cases of ruptured liver abscess. Raised Alkaline Phosphatase was found in most patients(92.67\%)Neutrophilic leukocytosis in $81.33 \%$ hypoalbuminemia in $70.67 \%$ and Raised Prothrombin Time 
$(86 \%-n=129)$ are the most important laboratory findings Raised AST/ALT were seen only in $26 \%$ of the patients and hyperbilirubinemia in 16\%.In USG studies solitary abscess was seen in $58.67 \%$ of cases, two cavities were found in $35.33 \%$ and multiple cavities in $6 \%$ of all the cases. Right lobe $(82.67 \%, \mathrm{n}=124)$ was commonly involved followed by both lobe involvement in $13.33 \%$ and isolated left lobe involvement in $4 \%$.

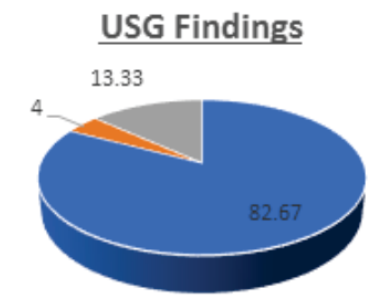

- Right Lobe " Left Lobe " Both Lobes

Graph No : 1

20 patients(13.33\%)recovered by conservative management. Rest 130 patients $(86.67 \%)$ required surgical intervention. Of them $55.4 \%$ underwent USG guided percutaneous aspiration and $41.5 \%$ of them had pigtail inserted under USG guidance. Rest of the 4 patients(3.1\%)with burst liver abscess underwent emergency laparotomy, who had their liver abscess burst into peritoneum at the time of presentation. Only 22 of the 130 pus samples send were culture positive $(14.67 \%)$. Most common organism isolated was E.coli $(40.91 \%, \mathrm{n}=9)$ [Graph No-2]

\section{Pus Microbiology}

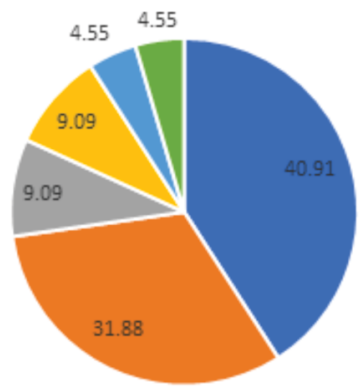

$$
\begin{aligned}
& \text { - E.coli } \text { - Klebsiella || Staph. } \\
& \text { - Pseudomonas = Bacter iods - Mixed flora }
\end{aligned}
$$

\section{Graph No 2}

Most common complication found was right sided pleural effusion seen in 25 patients $(16.67 \%)$.

Two patients expired thus with mortality of $1.33 \%$ and both were post laparotomy patients for burst liver

(Table No:1) Surgical Management of liver abscess and its complications

\begin{tabular}{|l|l|}
\hline Procedure done & Percentage \\
\hline Percutaneous Aspiration $(\mathrm{PA})$ & $55.4 \%(\mathrm{n}=72)$ \\
\hline Pigtail drainage $(\mathrm{PD})$ & $41.5 \%(\mathrm{n}=54)$ \\
\hline Laparotomy & $3.08 \%(\mathrm{n}=4)$ \\
\hline PA+ Pleural Tapping & $3.08 \%(\mathrm{n}=4)$ \\
\hline PA+ (R) ICD & $1.54 \%(\mathrm{n}=2)$ \\
\hline PD+ Pleural Tapping & $2.31 \%(\mathrm{n}=3)$ \\
\hline PD+ (R) ICD & $1.54 \%(\mathrm{n}=2)$ \\
\hline
\end{tabular}

\section{DISCUSSION :}

Liver abscess (LA) is common in the tropical region like the Indian subcontinent. The common etiological agents for LA are E. histolytica (amoebic), bacterial (pyogenic),M tuberculosis, and various fungi.

They tend to affect younger population especially males. Common presenting complains are abdominal pain, fever, and weight loss. Coexisting diarrhea occurs in $30 \%$ of patients and it is extremely rare to find amoebic trophozoites in the stool examination ${ }^{[3][4]}$.In our study the mean age is 42.54 years close to what was obtained in previous studies by Ghosh et al(41.13 years $)^{[4]}$ and Mukhopadyaya et al(43.64 years ${ }^{[5]}$ but higher than what was obtained another two studies by Mangukiya et al $(35 \text { years })^{[6]}$ and Trivedi et al $(31.5 \text { years })^{[7]}$ As far as sex predisposition was concerned only 12 females were present in our study with male to female ratio of 11.5:1 as was also seen in Ghosh et al and Mukhopadyaya et al having ratio of 13:1 and 11:1 respectively. The most common etiological factor for liver abscess in our study was alcoholism $(88.4 \%)$ similar to other studies ${ }^{[4]-[8]}$ All of our patients presented with complaints of abdominal pain same as in Mukhopadyaya et al ${ }^{[5]}$ and the most common site of pain was right upper quadrant of abdomen $(93.8 \%)^{[4]-[7]}$ Another uncommon complaint in liver abscess is cough. It is generally due to associated pleural effusion and compression collapse of the underlying lung parenchyma ${ }^{[4]}$ Cough as a symptom in our patients was present in $12 \%$ of patients. Previous series report it in $3.5-24 \%$ of cases ${ }^{[0]}$ Neutrophilic leukocytosis, raised alkaline phosphatase was found in majority of the patients in our study similar to previous studies ${ }^{[4]-[7]}$ Diarrhea was reported in $22 \%$ as also in study by Trivedi et al ${ }^{[9]}$ Etiologically E. coli being the most common pathogen found ${ }^{[4][7]}$ whereas klebsiella was the most common organism found in study by Mangukiya et $\mathrm{al}^{[6]} \mathrm{The}$ mortality rate of pyogenic liver abscess has been significantly reduced from 40 to $10-25 \%$ in past two decades ${ }^{[8]}$ Most common lobe involved is right lobe majority were solitary similar to previous studies ${ }^{[4-[7]} \mathrm{All}$ the patients were started empirically on IV $3^{\text {rd }}$ gen cephalosporins and IV metronidazole which was changed according to sensitivity report or clinical response. 20 patients $(13.33 \%)$ recovered by conservative management and rest required some form of surgical intervention. Most common complication encountered was right sided pleural effusion.

\section{Table 4: Complications of liver abscess.}

\begin{tabular}{|l|l|l|}
\hline & No of cases & Percentage \\
\hline 1.Pyothorax & 25 & 16.67 \\
\hline 2.Peritoneal rupture of liver abscess & 4 & 2.67 \\
\hline 3.Death & 2 & 1.33 \\
\hline
\end{tabular}

Two patients expired in our study who had undergone laparotomy for burst liver abscess with mortality rate of $1.33 \%$ which was significantly lower in other previous studies. The mortality rate in developed countries ranges from 2 to $12 \%{ }^{[10]}$.

\section{CONCLUSION :}

Middle age group males with history of alcoholic intake and belonging to poor socioeconomic class was the most common finding in our study. In this study overall mortality was low probably due to use of minimally invasive drainage techniques and etiology specific antimicrobials in all patients. Further large scale cohort studies are required to refine our understanding of various management methods.

\section{Conflict of Interests}

The authors declare that there is no conflict of interests regarding the publication of this paper.

\section{REFERENCES:}

1. Ochsner A, DeBakey M, Murray S. Pyogenic Abscess of the Liver II. An Analysis of Forty-Seven Cases with Review of the Literature. Am Jsurg. 1938;XL:292-319.

2. Wani RT. Socioeconomic status scales-modified Kuppuswamy and Udai Pareekh's scale Wani RT. Socioeconomic status scales-modified Kuppuswamy and Udai Pareekh's scale updated for 2019. J Family Med Prim Care [serial online] 2019 [cited 2020 Oct 1];8:1846-9.Avallable fom:htp:/www jenpc.com/extas?2019/8/6/1846/261413

4. Ghosh S, Sharma S, Gadpayle AK, Gupta HK, Mahajan RK, Sahoo R, et al. Clinical, laboratory, and management profile in patients of liver abscess from northern India. Journal Tropical Med. 2014;1:8

5. Mukhopadhyay M, Saha AK, Sarkar A, Mukherjee S. Amoebic liver abscess: presentation and complications. Indian J Surg. 2010;72(1):37-41

6. Mangukiya, Dhaval \& Darshan, Jitendra \& Kanani, Vijay \& Gupta, Saurabh. (2012). A Prospective Series Case Study of Pyogenic Liver Abscess: Recent Trands in Etiology and Mana 0397-0.

7. Dr. Miteshkumar Trivedi, Dr. Vipul Lad, Dr. Mohammed Anis and Dr Shiv Patel. Liver abscess: An observational study of clinical presentation and its management. abscess: An observational study of clinical presentation
International Journal of Surgery Science. 2019;3(1): 145-148.

8. Bergamini TM, Larson GM, Malangoni MA, et al. Liver abscess: review of a 12-yea experience. Am Surg. 1987;53:596-599.

9. S. L. Stanley Jr., "Amoebiasis: seminar," The Lancet, vol. 361, no.9362, pp. 1025-1034, 2003

10. Chen SC, Huang CC, Tsai SJ, et al. Severity of disease as main predictor for mortality in patients with pyogenic liver abscess. Am J Surg. 2009; 198: 164. doi:10.1016/ j.amjsurg.2008.08.022 